\title{
Políticas de solidariedade em acampamentos de fãs em shows de música pop ${ }^{1}$
}

\author{
Thiago Soares' \\ https://orcid.org/0000-0002-1305-4273 \\ I - UFPE \\ Recife (PE). Brasil
}

Resumo: Debate-se como os acampamentos de fãs em espetáculos de música pop internacionais que passam pelo Brasil são emblemáticos para se perceber a colonialidade (QUIJANO, 2010) e a reiteração performática de gestos em torno do fascínio pelo estrangeiro na cultura juvenil brasileira. Postula-se, a partir do debate sobre as Teorias da Performance e dos Estudos Culturais Latino-americanos, que os acampamentos encenam disputas, mas também solidariedade nas relações de vulnerabilidade e aliança (BUTLER, 2018) entre fãs de cultura pop no Brasil. A partir de três acampamentos de fãs ocorridos entre os anos de 2013 e 2017, debate-se que o "naturalizado" afeto brasileiro aponta para zonas tensivas da performance de ser fã: o sacrifício e a espera como apontamentos para o merecimento de estar perto da artista; as fabulações sobre o estrangeiro e as dimensões da cultura global no cotidiano e o fascínio pela imagem de poder atrelado a construções de cidadanias parciais de gênero e raça no campo da cultura.

Palavras-Chave: cultura pop; performance; acampamento de fãs; solidariedade; gênero.

Abstract: Solidarity policies in pop music concerts' fan camping sites - There is a debate on how fan camps of foreign pop music concerts that occur in Brazil are emblematic to perceive residues of the coloniality (QUIJANO, 2010) relations and the embodied performance of gestures around the fascination by the foreigner in Brazilian youth culture. It is postulated, from Performance theories and from Latin-American Cultural Studies, that these camps stage disputes, but also solidarity upon vulnerability and alliance relations (BUTLER, 2018) among fans of pop culture. From three fan camps between the years of 2013 and 2017, we postulate that the "naturalized" Brazilian affection points to tension zones of the performance of being a fan: the sacrifice and the waiting as notes for the merit of being near the artist; the fabulations about the foreigner and about the dimensions of global culture in everyday life as well as the

1 Texto revisado e ampliado a partir do que foi apresentado ao GT História do Jornalismo no $11^{\circ}$ Encontro Nacional de História da Mídia, evento realizado de 19 a 21 de junho de 2019 em Natal (RN), sediado pela Universidade Federal do Rio Grande do Norte e promovido pela Associação Brasileira de Pesquisadores da História da Mídia. 
fascination with the image of power linked to constructions of partial citizenship of gender and race in the field of culture.

Keywords: pop culture; performance; fan camp; solidarity; gender.

Observa-se uma prática comum em shows de artistas musicais pop internacionais que apresentam suas turnês no Brasil: o acampamento de fãs nas áreas dos arredores de estádios, arenas ou casas de espetáculo, como tentativa de demonstração de afeto e performatização de sacrifício nas disputas destes fãs pela atenção dos ídolos. Com intervalos que duram, em média, entre duas semanas e até cinco meses antes dos espetáculos, os acampamentos de fãs nos shows musicais de artistas pop no Brasil colocam em evidência uma relação ambígua e performática nas práticas e experiências de fãs. Este artigo toma a prática de acampamento de fãs em espetáculos musicais pop² como parte da construção de uma cultura performática brasileira de fãs sobre a relação com ídolos pop internacionais, seus roteiros, personagens e dramas, ao mesmo tempo que postula a construção de teatralidades nas performances midiáticas de espera e sacrifício como aparatos de engajamento e da forma singular como a cultura de fãs se desenha no contexto brasileiro.

Especula-se sobre relações mais amplas entre Norte e Sul Global ${ }^{3}$ nas corporalidades de fãs brasileiros, com base na maneira com que dizem, encenam e fabulam relações de proximidade e distância com artistas e seus agenciamentos em contextos midiáticos de alta visibilidade. Os acampamentos de fãs seriam formas de compreender traços da colonialidade (QUIJANO, 2010) que se apresentam performaticamente nos tecidos urbanos e no cotidiano das metrópoles brasileiras na medida em que, por meio do contato com espetáculos musicais da cultura pop, colocam-se em disputa diferentes noções do que é ser cosmopolita no Brasil - valores largamente consagrados na cultura de fãs de artistas de música pop. Entende-se que as práticas de fãs de música pop são atravessadas por marcadores de classes sociais, gênero e raça (quem pode comprar produtos de seus ídolos, que performances de gênero são encenadas nos espaços, quais acionamentos emergem a partir da presença de pessoas negras ou pobres em shows de altos valores de ingressos) e que os acampamentos de fãs fora dos estádios e casas de espetáculo seriam ambientes mais tensivos no tocante às marcações sociais, pois incorporariam a lógica das ruas às dinâmicas performáticas da cultura pop.

2 É importante ressaltar que os acampamentos de fãs não são exclusividade de espetáculos de música pop, tampouco do Brasil. Fazem parte de uma memória corporal de eventos da cultura pop e trazem inscritas marcas temporais e territoriais quando ocorrem. Em 1969, fãs acamparam por três dias em uma fazenda no interior do Estado de Nova York para assistir ao festival de rock Woodstock. Em 1973, houve acampamento de fãs na porta do teatro em que a soprano Maria Callas faria sua turnê de despedida em Nova York. Este artigo, entretanto, debate marcas performáticas e territoriais dos acampamentos de fãs no Brasil.

3 Sul global é um termo utilizado em estudos pós-coloniais que pode referir-se ao conjunto de países em desenvolvimento, incluindo as regiões mais pobres do mundo (em geral ao sul do Hemisfério) em oposição aos países mais ricos (do Norte global). O termo serve como metáfora para países que têm uma história interconectada de colonialismo, neocolonialismo e uma estrutura social e econômica com grandes desigualdades em padrões de vida, esperança, vulnerabilidade e acesso a recursos básicos de vida. 
Entende-se por cultura pop o conjunto de práticas, experiências e produtos norteados pela lógica midiática, que tem como gênese o entretenimento; se ancora, em grande parte, a partir de modos de produção ligados às indústrias da cultura (música, cinema, televisão, editorial, entre outras) e estabelece formas de fruição e consumo que permeiam um senso de comunidade, pertencimento ou compartilhamento de afinidades que situam indivíduos dentro de um sentido transnacional e global.

É importante problematizar que sensos de comunidade, pertencimento e partilha estão em disputa na cultura pop na medida em que ideais sobre o transnacional, o global e, portanto,o cosmopolitismo estão atravessados por princípios basilares do capitalismo - portanto, em que medida o consumo de produtos de cultura pop, para além da ideia de empoderar sujeitos por meio de pautas identitárias, sobretudo de gênero e de raça, também não seria exímio em fazer enxergar as desigualdades e assimetrias do consumo das sociedades em contextos da América Latina (CANCLINI, 2008)?

Entende-se que eventos de música pop com artistas internacionais em contextos de marcadas desigualdades sociais evidenciam traços identitários que colocam em crise a categoria de Nação, funcionando como dispositivo autorreflexivo sobre o que significa ser fã e ser brasileiro/ latino/ argentino/ peruano etc. ao se reconhecer como parte de um sistema global de consumo marcadamente anglófono e centrado no conjunto de imagens, sons e história que consagram a cultura dos Estados Unidos. Dois movimentos podem ser pensados a partir desta relação: sobre o deslocamento histórico do imaginário metropolitano da cultura - de cidades como Paris e Roma (e, portanto, da Europa) para Nova York, Los Angeles e Miami (ou seja, os Estados Unidos) (CANCLINI, 2005) e sobre a naturalização de ideais de modernidade e cosmopolitismo que estão "fora" dos países da América Latina, mais especificamente no Norte Global, reiterando narrativas sobre deslocamentos, migrações e diásporas de sujeitos do Sul Global.

Este artigo se estrutura em três partes: na primeira, debate-se um conjunto de práticas performáticas em acampamentos de fãs nas cidades de São Paulo e Rio de Janeiro que evidenciam "mal-entendidos culturais" a partir de diferentes noções do que seria performar amor e devoção ao ídolo no contexto brasileiro. Questionam-se interpretações consagradas sobre a cordialidade brasileira na medida em que acampamentos de fãs seriam espaços de disputa e de autoridade tanto online como offline, como já atestaram Sá (2016) e Amaral e Monteiro (2013). Na segunda parte, a partir de um olhar mais detido sobre o documentário "Waiting for B", que registra o cotidiano de fãs mulheres e LGBTQ+ ${ }^{4}$ acampados e esperando pelo show da cantora Beyoncé, em 2013, na cidade de São Paulo, são traçadas considerações sobre o que Judith Butler vai chamar de políticas de solidariedade em assembleias públicas: mesmo em meio a espaços de incessantes disputas como são os acampamentos de fãs, é possível o reconhecimento da vulnerabilidade de

4 LGBTQ+é uma sigla que compreende indivíduos classificados amplamente como homossexuais e variantes de gênero, ou seja, Lésbicas, Gays, Bissexuais, Travestis, Transexuais, Transgêneros e sujeitos queer (desviantes). 
sujeitos LGBTQ+ e a formação de redes de apoio coletivos como parte do entendimento sobre marcações sociais de gênero e raça no tecido urbano. Na terceira parte, discute-se como acampamentos de fãs podem ancorar questionamentos sobre o que significa o consumo de música pop e mais amplamente de cultura pop na América Latina.

Do ponto de vista metodológico, trata-se de uma pesquisa sobre diferentes mediações sobre acampamentos de fãs, na medida em que a escolha dos três acampamentos de fãs analisados (para os shows de Beyoncé em 2013 e de Justin Bieber e Lady Gaga em 2017) é atravessada por distintas formas de midiatização destes espaços e de seus personagens. Enquanto reportagens jornalísticas na internet e na televisão (usadas como amostras para os acampamentos nos shows do Rio de Janeiro) tratam de dramatizar os acampamentos de fãs a partir de um enfoque temporalmente comprimido, o documentário "Waiting for B", ao contrário, preocupa-se em traduzir a ideia de convivência e cotidianidade entre fãs, ampliando o espectro de questionamentos propostos.

Coloca-se também o problema metodológico em torno dos questionamentos sobre a densidade das reflexões que se amparam em interpretar uma efemeridade - um acampamento de fãs de poucas semanas ou de alguns meses. Neste sentido, a argumentação deste artigo sustenta-se sobre um debate contemplado nos Estudos de Performance que aponta para a crise da hermenêutica a partir da entrada de um tipo de enfoque que considere a efemeridade como um traço característico de fenômenos sociais a serem analisados e não um entrave. "As performances não podem nos dar acesso a outra cultura, permitindo vê-la em profundidade, mas elas certamente nos dizem muito sobre nosso desejo desse acesso e refletem a política de nossas interpretações" (TAYLOR, 2013, p. 32).

\section{Performance de fãs e "mal-entendidos" culturais}

Comecemos por dois acampamentos de fãs ocorridos no ano de $2017^{5}$, em duas cidades distintas do Brasil (São Paulo e Rio de Janeiro) e que lançam hipóteses sobre endereçamentos performáticos de fãs e suas vivências afetivas em rede: 1. o acampamento de fãs que durou cinco meses quando da ocasião da vinda do cantor Justin Bieber para a cidade de São Paulo e 2. o acampamento de fãs que se formou quando do anúncio do cancelamento do show da cantora Lady Gaga no Rock in Rio, no Rio de Janeiro. Estes dois acampamentos trazem à tona paradoxos das relações entre fãs e artistas, assim como colocam em pauta diferentes formas de lidar com as noções de proximidade e distância dos fãs com seus ídolos no contexto brasileiro.

5 A escolha dos dois acampamentos está norteada pela singularidade no tocante à questão temporal: o referente ao show de Justin Bieber no Brasil, foi, até então, o mais longo acampamento de fãs no Brasil (durou cinco meses), em contrapartida, o referente ao cancelamento do show de Lady Gaga no Rock in Rio, no Rio de Janeiro, teria durado dois dias. Entendemos que a variação temporal em torno dos acampamentos requer diferentes formas de abordagens sobre as naturezas performáticas ali apresentadas, porém, ambos reiteram um traço característico da organização de fãs brasileiros quando da passagem de shows internacionais no País. 
No mês de abril de 2017, o cantor Justin Bieber aportou para show na cidade de São Paulo como parte da Porpuse Tour. Cinco meses antes, em novembro de 2016, entretanto, já havia grupos de fãs acampados nos arredores da arena para esperar pelo ídolo. Dias antes do início do show, uma suposta tentativa de mudança da entrada de acesso à arena foi noticiada ${ }^{6}$. O intuito seria coibir que fãs mais afoitos que estavam acampando durante cinco meses na porta do estádio ficassem próximos demais ao artista. Após mobilizações em rede e diversos desmentidos sobre as ações da produção do espetáculo, este episódio marca importante reconhecimento da ambiguidade do afeto dos fãs nos sistemas produtivos do entretenimento, acionando refletir sobre formas de controle e gestão de imagem de artistas em ambientes midiáticos. O questionamento e a recusa em torno do excesso de afeto por parte dos fãs brasileiros, que frequentemente se orgulham da afetividade e da empolgação como traços "naturais" da alegria brasileira, são formas de mapear contradições em torno da territorialização de fenômenos globais no Brasil.

A euforia, vista, por parte dos fãs, como uma qualidade e uma singularidade de uma apresentação realizada no Brasil, pode converter-se em sutis formas de violência. Destaco esta controvérsia em torno do excesso de afeto do público brasileiro e de sua contenção por parte da produção internacional do espetáculo musical como aquilo que Jesús MartinBarbero (2003) vai chamar de mal-entendidos culturais - numa linhagem mais ampla, parte dos problemas da interculturalidade (CANCLINI, 2008 e 2009) e das disputas de sentido que ocorrem nas epistemes da cultura. Aquilo que seria "o melhor" do brasileiro - seu amor, seu afeto, seu carinho - parecem invasivos aos olhares dos estrangeiros.

Tratemos de outra relação do excesso de afeto dos fãs brasileiros. Em setembro de 2017, um dia antes de sua apresentação, a cantora Lady Gaga cancela a participação no Rock in Rio, na cidade do Rio de Janeiro. Um acampamento de fãs pós-cancelamento se forma diante do hotel em que a artista se hospedaria no bairro de Ipanema. O que seria uma reunião de fãs lamentando o cancelamento se converte numa performance coletiva de tristeza e luto, mas também de carnavalização e euforia diante da presença de equipes de televisão que registravam o ocorrido. Fãs de diversas localidades do Brasil que tinham ido ao Rio de Janeiro especialmente para o espetáculo de Lady Gaga se dirigiram para a porta do hotel em que emissoras de televisão transmitiam flashes ao vivo com o lamento dos fãs para se somarem à corrente de tristeza pela não-vinda de Lady Gaga. Palavras como "desespero", tristeza profunda e luto aparecem nas narrações sobre o acontecido $^{7}$ ao mesmo tempo em que contrastam com as imagens de fãs fantasiados da artista, que choravam e pareciam "curar" a tristeza performatizando o amor pela cantora pop exibindo-se para as emissoras de TV.

6 Para mais informações: https://g1.globo.com/e-ou-nao-e/noticia/bieber-mandou-mudar-a-fila-de-lugar-e-os-fasacampados-se-deram-mal-nao-e-verdade.ghtml

7 Para mais informações: https://g1.globo.com/musica/rock-in-rio/2017/noticia/fas-se-desesperam-comcancelamento-de-show-da-lady-gaga-no-rock-in-rio.ghtml 
Em um dos vídeos mais emblemáticos que foi compartilhado durante o acampamento pós-cancelamento do show de Lady Gaga, um fã fabula sobre o possível cancelamento do espetáculo dizendo, para o repórter da Globo News, em tom sério e cético, que tinha atirado uma Bíblia na cantora e que, desde então, ela teria cancelado diversas apresentações após o acontecido ${ }^{8}$. A mistura de tristeza com possibilidades performáticas e de construção de notoriedade funcionam como estratégia de fãs diante de amplos processos de performatização em mídias. Desenha-se um roteiro performático (TAYLOR, 2013) em que o luto se carnavaliza na medida em que se midiatiza, construindo um dispositivo estético perpassado pelo melodrama, pelo kitsch e pelos acionamentos de uma precariedade em torno das pequenas alegrias da vida.

Os acampamentos de fãs em shows de artistas pop em passagem pelo Brasil são lugares privilegiados de entendimento das dimensões performáticas e culturais de encenação de disputas, afetos e teatralização de dramas ligados à juventude brasileira. Parte desta juventude performatiza seus afetos em um dentro-fora nas relações interculturais: aquilo que os jovens brasileiros reconhecem ser sua singularidade e, portanto, sua força e potencial de engajamento de notoriedade numa cultura pop global é também a forma problemática e perigosa com que esta singularidade se apresenta - sobretudo em espetáculos de grande aglomeração de pessoas - com possibilidade até de catástrofes e mortes de fãs que foram apenas ver seus ídolos ${ }^{9}$, como no episódio em que três pessoas morreram pisoteadas durante um evento com o grupo mexicano RBD num estacionamento de um supermercado em São Paulo no ano de 2006.

Os dois acampamentos aqui relatados funcionam, portanto, como formas de entendimento sobre espontaneidade e controle de afetos e ações na cultura do entretenimento se territorializando no Brasil. A seguir, me deterei mais atentamente ao documentário Waiting for $B$ na tentativa de elaborar conexões sobre performance, espera e sacrifício de fãs em ambientes de redes e, ao mesmo tempo, sobre as políticas de solidariedade existentes nestes espaços.

\section{Disputas, alianças e precariedades em acampamentos de fãs}

Se pensarmos na geopolítica mundial e nas assimetrias entre países, além da própria centralidade de grande parte da produção midiática global, o fascínio que produtos da cultura pop exerce sobre jovens brasileiros pode ser identificado por meio da forma enfática, direta e insistente com que estes jovens interagem com seus ídolos nas redes sociais digitais e realçando traços identitários em contextos transculturais (AMARAL, 2016). De tanto comentarem "Please Come to Brasil" ("Por favor venha para o Brasil" ou \#PleaseComeToBrazil) em fotos no Instagram ou em posts no Facebook, por exemplo, parte da juventude brasileira é tratada com ironia, desdém e certa dose de ingenuidade

8 Para a íntegra do vídeo: https://www.youtube.com/watch?v=Yfe0nK6LiOk

9 Para mais informações: https://www1.folha.uol.com.br/fsp/cotidian/ff0502200622.htm 
em ambientes digitais - como ressaltam Castellano e Machado (2017) ao analisarem a hashtag \#PleaseComeToBrazil como estratégia de engajamento entre fãs e drag queens no contexto brasileiro na série Ru Paul's Drag Race.

Com base na ideia de que a cultura pop opera sobre os imaginários dos sujeitos, criando zonas de experiência com o Outro por meio de discursos presentes em sistemas mainstream da indústria do entretenimento, identificam-se ídolos pop como vetores de entendimento, representação, performance e identidade de questões que atravessam a ideia de Nação e apontam para disputas em torno das noções de poder atreladas a marcadores sociais, como classe social, raça e gênero. Investigar acampamentos de fãs em espetáculos de música pop no Brasil significa refletir sobre as diferentes marcações sociais presentes na sociedade brasileira a partir de acionamentos gerados em sistemas midiáticos e transnacionais de consumo.

Toma-se a espera dos fãs como um quadro performativo, na medida em que "a performatividade é um modo de nomear um poder que a linguagem tem de produzir uma nova situação ou de acionar um conjunto de efeitos" (BUTLER, 2018, p. 35). Grande parte desta espera se dá dançando, fazendo coreografias de videoclipes e performances para serem registradas e divulgadas em redes sociais digitais. Essa vivência performática em rede aciona pensarmos sobre como os acampamentos de fãs que se formam na ocasião da passagem de artistas pop pelo Brasil são lugares de fabulações tanto sobre imagens utópicas de felicidade e superação quanto de performatividade de condições de classe social, raça e gênero dentro de espectros consagrados midiaticamente.

O acampamento de fãs na espera da cantora Beyoncé, em São Paulo, disposto no filme Waiting for $B$, dos diretores Paulo César Toledo e Abigail Spindel, situa a figura da cantora negra norte-americana como articuladora de uma "comunidade interpretativa" de fãs, como aponta Sandvoss (2013), promovendo engajamento e comprometimento emocional com determinadas narrativas e textos. Em estudo sobre como fãs incorporam ídolos num recurso simbólico de bastante relevância para suas vidas, John Fiske (1992) demonstrou diferentes entendimentos de como fãs reconhecem uma pedagogia de seus atos a partir da vida de seus ídolos e dinâmicas de autorreflexividade sobre suas tomadas de decisões no cotidiano.

Uma das personagens do filme Waiting for B, é Junnior Martins, que trabalha como cabeleireiro na Região Metropolitana de São Paulo e encara deslocamento de três horas para a vigília no estádio. Ir para o acampamento de fãs, para além do encontro com outros fãs da cantora, significava também menos horas trabalhadas - já que seu atendimento a clientes no salão de beleza também envolvia finais de semana. Outra personagem presente no documentário é Gabriela Electra, que se apresentava em casas noturnas, festas de aniversário e eventos em geral como cover de Beyoncé, ou seja, cantar e imitar a cantora norte-americana era parte de seu sustento financeiro. Tanto nas criações da atividade de cabeleireiro de Junnior Martins quanto na performance de Gabriela Electra 
em apresentações de dublagem, a figura de Beyoncé é central para o desempenho no ambiente de trabalho.

A ênfase nos personagens de Waiting for $B$ recai sobre as relações entre trabalho e diversão/ lazer, evidenciando para além de uma lógica binária que iria opor estas atividades como constitutivas de um cotidiano em que o trabalho se espraia em todas as esferas da temporalidade dos sujeitos. Os acampamentos de fãs seriam ambientes em que o compartilhamento das trajetórias de fãs em suas dificuldades financeiras cotidianas encontram a trajetória da cantora Beyoncé - uma mulher negra do sul dos Estados Unidos que, pela ação dos pais, ainda quando criança, entra para o mercado de música e entretenimento e se constrói como uma das mais ricas artistas na indústria da cultura pop. O marcador de classe social de fãs brasileiros reunidos nos acampamentos coloca em disputa ideais de riqueza e poder atrelados a celebridades, ao mesmo tempo em que aciona a autorreflexão sobre suas condições de classe, limites e potências no contexto brasileiro.

O marcador de classe social aparece interseccionado nos de gênero e raça nos acampamentos de fãs da cantora Beyoncé. As personagens presentes no documentário Waiting for B debatem as condições de sujeitos LGBTQ+ e de mulheres em seus convívios diários ao relatarem suas dificuldades ligadas a temas como orgulho gay, homofobia e feminismo. A homofobia é retratada na obra a partir da tensão gerada entre os fãs de Beyoncé acampados no Estádio do Morumbi com as torcidas organizadas de times de futebol em dias de jogo. Os grupos de sujeitos LGBTQ+ e de mulheres que acampam na espera por Beyoncé são hostilizados pelos torcedores de futebol que julgam o ato de esperar pela artista como uma bobagem, coisa fútil e de bicha. Um conjunto de valores ligados à depreciação de ações realizadas por mulheres, gays e lésbicas como menores ou menos importantes colocam homens gays e mulheres em sistemas de aliança a partir de lógicas de vulnerabilidade que emergem em contextos tensivos. Aquelas mulheres e gays

passam a significar justamente o oposto nessa situação, uma vez que, reunidos, reforçam seus estilos, reafirmam suas identidades e atuam nestas práticas comunicacionais. Os sinais evidentes dessa "marginalidade normativa" refletem os significados sociológicos desses fãs e adquirem força, principalmente, ao transformarem o Morumbi, o "templo da heterossexualidade", em um acampamento gay (MAUREY, 2018, p. 214).

É da tensão entre sujeitos que emergem as vulnerabilidades e as alianças. Ou aquilo que Judith Butler vai chamar de políticas de solidariedade, que seriam formas de união, resistência e autoproteção pautadas pela emergência de situações de vulnerabilidades, evidenciando as assimetrias entre sujeitos - que corpos são passíveis de serem agredidos, insultados e mortos. É na construção do clima de tensão entre fãs de Beyoncé e torcedores de futebol realçados no escopo do documentário Waiting for $B$ que se evidencia a construção de uma política de solidariedade. Os acampamentos de fãs em áreas 
externas a estádios e casas de show no Brasil colocam em evidência noções de risco e exposição à violência, realçando também traços das desigualdades brasileiras. É neste quadro performático que conecta entretenimento e lazer a risco e violência que emerge o enquadramento da figura dos fãs com base na ideia da vida precária.

Reitera-se a necessidade de pensar os espaços de encontros de fãs de cultura pop como ambientes políticos que reforçam a formação de consensos em torno do afeto por determinados produtos ou artistas, mas também e sobretudo como ambientes geradores de dissensos e de desentendimentos sobre aspectos micro ou macropolíticos. Comecemos tratando de que natureza política agregadora os acampamentos de fãs assumem.

A força indexal do corpo que se une para protestar por emprego, moradia, educação e saúde públicas, em contextos de manifestações e ocupações (foco da reflexão de Butler), pode ser pensada também dentro do escopo da exposição das vulnerabilidades individuais ou coletivas e possibilidades de resistência a cotidianos adversos por meio do estabelecimento de redes de solidariedade que se sedimentam em espetáculos da cultura pop. Pondero recorrer ao pensamento de Butler, amplamente centrado na filosofia política, e de suas ideias sobre vida precária e aliança dos corpos, para me dirigir a fenômenos comumente interpretados como apolíticos ou fúteis, relatados midiaticamente pela rubrica dos distúrbios de comportamento ${ }^{10}$. Parece-me, no entanto, oportuno tratá-los a partir de uma reconfiguração da noção de política a partir da premissa de que existe uma força que agrega fãs em acampamentos, uma natureza particular do afeto que, de alguma forma, parece querer narrar sua condição precária, suas ações corpóreas e reivindicar formas de liberdade que pertencem à assembleia pública - sobretudo se pensarmos no que Butler vai chamar de direito de aparecer tendo em vista os alarmantes números de feminicídios ${ }^{11}$ e crimes de homofobia no Brasil ${ }^{12}$.

Delimita-se um traço parcial e significativo sobre fãs de artistas pop no Brasil: sujeitos pobres, submetidos à insegurança e à desesperança, com trabalhos temporários, sem amparo de serviços sociais e fora dos radares ativos da cidadania, que encontram rede de apoio mútuo e maneiras de resistir à "sensação de ser dispensável ou descartado no tecido social" (BUTLER, 2018, p. 21). A vivência coletiva dos acampamentos parece colocar em questão valores ligados a aprendizados sobre formas de lidar com dificuldades cotidianas e sensos comunitários de pertencimento como maneiras de organização e planejamento da própria vida. "A assembleia desempenha o papel de uma força provisória e plural de coexistência que constitui uma alternativa ética e social distinta" (BUTLER, 2018, p. 22).

10 Destaco o tratamento patológico que reportagem do programa Fantástico realizou em 26 de maio de 2019, questionando "o que se passaria na cabeça de um fã" que passa três meses acampado esperando por um ídolo. Para detalhes: https://g1.globo.com/fantastico/noticia/2019/05/26/o-que-se-passa-no-cerebro-de-um-fafantastico-faz-testes-em-busca-de-resposta.ghtml.

11 Brasil é o quinto colocado em taxas de feminicídio no mundo, segundo a Organização Mundial da Saúde (OMS). Para mais informações: https://exame.abril.com.br/brasil/taxa-de-feminicidios-no-brasil-e-a-quintamaior-do-mundo/

12 Registro de reportagem do portal Uol atesta que a cada 16 horas, acontece um crime de homofobia ou LGBTfobia no Brasil. Para mais informações: https://noticias.uol.com.br/cotidiano/ultimas-noticias/2019/02/20/brasil-matou8-mil-lgbt-desde-1963-governo-dificulta-divulgacao-de-dados.htm 


\section{Colonialidade nos protocolos de Estudos sobre Cultura Pop no Brasil}

A certa altura do filme Waiting for $B$, um fã de Beyoncé relata o desejo de conhecer os Estados Unidos, destila uma série de críticas ao Brasil, fazendo-nos refletir sobre as articulações das imagens midiáticas de poder da artista e modelos de enquadramento do mundo através de lógicas neoliberais fortemente ancoradas em estilos de vida dos Estados Unidos. Inscreve-se no quadro uma dupla precariedade: a de ser um sujeito LGBT e também brasileiro. Dentro de um quadro teórico que propõe enxergar os traços das relações coloniais presentes no cotidiano dos países da América Latina, Aníbal Quijano (2010) desenvolve o conceito de colonialidade do poder para tentar entender as estruturas de valores socioculturais que seguem inscritas nas disposições políticas destes países. Para o autor, o sistema colonial instaura ideais de modernidade que passam pelo eurocentrismo, pela incorporação de uma série de disposições culturais, sociais e políticas que estariam fora da América Latina e que passam a ordenar e legislar a vida nas colônias a partir de divisões e clivagens amparadas em saberes originários de contextos europeus. A ideia de colonialidade, vista como um sistema de valores que distingue civilizados (metropolitanos) e primitivos (nativos), mas também que se espraia para a própria ciência (incorporação de saberes europeus em detrimento daqueles originários dos próprios contextos), instaura um conjunto de normas na vida das cidades e das Nações que seria resultado de uma série de ações que chegariam ao campo da cultura. A consagração de artistas estrangeiros na colônia brasileira, o financiamento de pintores brasileiros que estudassem na Europa, e a reprodução de padrões literários luso-hispânicos na literatura nacional foram traços da reiteração da colonialidade do poder no campo da cultura.

A partir de uma virada no Pós-Guerra e a emergência dos Estados Unidos como potência econômica e cultural, tem-se um reordenamento do quadro geopolítico e cultural na América Latina. Canclini (2005 e 2009) destaca que, a partir de uma ênfase no aspecto econômico da cultura, a produção cultural dos Estados Unidos (no campo da música, do cinema e da televisão sobretudo) desloca o eixo eurocêntrico da colonialidade (presente sobretudo no século XIX) para aquela que se instaura midiaticamente no século XX a partir do destacamento de Hollywood, da Music Television, das grandes gravadoras musicais multinacionais etc. Os produtos da cultura pop seriam, portanto, exímios em evidenciar traços da colonialidade em resíduos culturais que permaneceriam nas relações entre sujeitos coloniais e produções culturais estrangeiras. Ressalta-se a necessidade de pensar as negociações existentes no campo da cultura que colocam em evidência estes traços da colonialidade. É nessa direção que se percebe como a cultura pop é um fértil campo para se entender instâncias de poder geopolíticas no campo da cultura e das mídias, ao mesmo tempo em que percebemos as rasuras culturais que emergem nesses processos.

$\mathrm{Na}$ larga tradição sobre estudos sobre cultura popular e mais detidamente sobre música popular na América Latina, é oportuno trazer à tona a questão do pop. Primeiro, 
porque o pop no contexto da América Latina pode significar tanto a cristalização de uma história de dominação e pregnância de um imaginário ligado aos Estados Unidos e dos fenômenos de língua inglesa no contexto latino-americano, quanto apontar para tramas de territorialização destes fenômenos em contextos singulares, ressignificando os aportes em torno de noções estanques sobre imperialismo e guerras culturais.

Obviamente que não se oblitera a força econômica de fenômenos da cultura pop e sua capacidade de silenciar ou atenuar disposições locais. No entanto, aposta-se no tecido social como poroso, difuso, inacabado e também tensivo, acarretando em formas de produção e fruição híbridas nos mais diversos países da América Latina. Estudar o pop neste contexto significa tentar entender as tramas de memória, fascínio, ojeriza e resistência que fizeram/fazem parte das relações entre metrópoles-colônias, conquistadores-conquistados (CANCLINI, 2005).

A questão da colonialidade é inserida no debate sobre cultura pop a partir de diferentes traços acionados nos fenômenos analisáveis. No caso dos acampamentos de fãs, ressalta-se a presença de resíduos performáticos que remontam à religiosidade cristã nas relações de disputa e solidariedade como evidência das disposições coloniais reiteradas no cotidiano. A questão do sacrifício de estar dias e até meses à espera do seu ídolo, as privações alimentares e também de sono, bem como as maneiras com que encenam o desejo de estar diante do artista soam como formas cristãs consagradas de performatividade. Tomando o cristianismo como principal traço da colonialidade do poder na dimensão religiosa, percebe-se como, por meio da consagração de rituais ligados às liturgias das igrejas, instaura-se uma série de valores que vão se construindo como consensuais sobre formas legítimas de adoração.

Observar fãs que se relatam pelo sofrimento e pela dor em acampamentos nos arredores de estádios e casas de show nas metrópoles brasileiras é uma forma de compreender como os enquadramentos da colonialidade do poder se fazem presentes nos gestos e escolhas por formas de autorregulação. Se tomarmos o cristianismo como a principal ferramenta de catequese e de docilização dos corpos nativos no processo colonial, teríamos os fãs em seus afãs e desejos de presença e de sacrifício como inscritos no roteiro performático da colonização (TAYLOR, 2013) que ainda se atualiza e se materializa nos corpos dos sujeitos. Este roteiro, entretanto, se atualiza a partir de novas narrativas que se inserem e problematizam os marcadores coloniais. A carnavalização, a jocosidade e a autoironia aparecem como respostas nestas negociações performáticas no campo da cultura.

\section{Considerações finais}

Procuramos refletir sobre a singularidade da experiência de fãs de artistas pop internacionais no Brasil como sintoma de uma relação colonial que deixa resíduos 
no tocante a precariedade, vulnerabilidade e alianças de corpos no contexto da América Latina. Fãs brasileiros, na medida em que formam acampamentos para aguardar seus artistas preferidos, colocam em evidências gestos afetivos ambíguos que parecem retomar os rituais de contato entre estrangeiros e nativos em processos coloniais ao mesmo tempo que encenam impasses culturais destas relações. Entende-se que a espera e o sacrifício são partes de um roteiro performático que pressupõe deliberadamente se aproximar de seus ídolos a partir de dispositivos de mídia e mediadores que funcionem como acesso ao universo codificado do espetáculo e do entretenimento.

Há três aspectos performáticos na espera em acampamentos de fãs que colocam em evidência as relações de parte da juventude brasileira com artistas pop: 1) o fascínio pela imagem do ídolo e empreendedor que se constrói a partir de valores da cultura de entretenimento ocidental e sua territorialização no contexto brasileiro; 2) a performatização do sacrifício por estar próximo ao ídolo pop como uma disposição de estruturas coloniais da relação nativos-estrangeiros apontando pela forma carnavalizada e festiva de tratar o sacrifício como marcas também destas relações coloniais; 3) a marcação racial e de gênero dos fãs como acionadoras de sublimação de precariedades com base na negociação com as tessituras de intrigas que se formam a partir das narrativas presentes na cultura pop, evidenciando cidadanias culturais e maneiras de entendimento de mundo que são acionadas pela relação com a cultura pop.

O debate sobre cultura de fãs, universo do trabalho e desigualdades sociais que se apresentam nos acampamentos de fãs demanda movimentos epistemológicos que nos direcionam para os enlaces entre estudos sobre cultura pop e seus impactos simbólicos no cotidiano dos sujeitos; sobre a especificidade da cultura de fãs no Brasil e na América Latina e sobre a maneira com que respondemos aos convites do cosmopolitismo e da globalização.

Thiago Soares é professor do Programa de Pós-graduação em Comunicação da UFPE.

thikos@gmail.com

\section{Referências}

AMARAL, A,; MONTEIRO, C. Esses roqueiro não curte!: performance de gosto e fãs de música no unidos contra o rock do Facebook. Revista da Famecos, Porto Alegre, v. 20, n. 2, p. 446-471, maio/ago., 2013.

AUSLANDER, P. Liveness: performance in a mediatized culture. Londres: Routledge, 2012.

BATESON, G. A theory of play and fantasy. In: SALEN, K.; ZIMMERMAN, E. The game designer reader: the rules of play anthology. Cambridge: MIT Press, 2006. p. 114-128.

BHABHA, H. K. O bazar global e o clube dos cavalheiros ingleses. Rio de Janeiro: Rocco, 2012.

BUTLER, J. Bodies that matter: on the discursive limits of sex. Nova York: Routledge, 1993. 
Problemas de Gênero: feminismo e subversão de identidade. $3^{a}$ edição. Rio de Janeiro: Civilização Brasileira, 2010. 2015.

Quadros de guerra: quando a vida é passível de luto? Rio de Janeiro: Civilização Brasileira,

Corpos em aliança e a política das ruas: notas para uma teoria performativa de assembleia. Rio de Janeiro: Civilização Brasileira, 2018.

CANCLINI, N. G.. Consumidores e cidadãos. Rio de Janeiro: Editora da UFRJ, 2005.

. Latino-Americanos à procura de um lugar neste século. São Paulo: Iluminuras, 2008.

. Diferentes, desiguais e desconectados. Rio de Janeiro: Editora da UFRJ, 2009.

CASTELlanO, M. e MACHADO, H. "Please Come to Brazil!" The Practices of RuPaul's Drag Race's Brazilian fandom. In: BRENNAN, N., GUDELUNAS, D. (eds.). RuPaul's Drag Race and the Shifting Visibility of Drag Culture. Palgrave Macmillan, Cham: 2017. p. 167-177.

DE CERTEAU, M. A invenção do cotidiano: artes de fazer. 21.ed. São Paulo: Vozes, 2014.

DENORA, T. Music in everyday life. Cambridge: Cambridge University Press, 2000.

FISKE, J. The cultural economy of fandom. In: LEWIS, L. A. (ed.) The adoring audience. London: Routledge, 1992.

FRITH, S. Music for pleasure: essays in the sociology of pop. Cambridge, Polity, 1988.

Performing rites: on the value of popular music. Harvard: Harvard University Press, 1996.

JANOTTI, J.; SÁ, S. P. Cenas musicais. Rio de Janeiro: Editora da Ana, 2013.

MARTÍN-BARBERO, J. Dos meios às mediações: comunicação, cultura e hegemonia. 2. ed. Rio de Janeiro: Ed. UFRJ, 2003.

MAUREY, A. As culturas juvenis: a espera como participação social e autoafirmação no filme Waiting for B. Trama: Indústria Criativa em Revista, n. 6, v. 1. Disponível em: http://revistapuca.estacio.br/ index.php/trama/article/view/5591/12. Acesso em: 13 maio 2019.

QUIJANO, A. Colonialidade do Poder e Classificação Social. In: SANTOS, B.S. e MENESES, P.M. Epistemologias do Sul. Coimbra: Edições Almedina, 2010. p. 73-118.

$\mathrm{ROACH}$, J. Cities of the dead: Circum-Atlantic performance. New York: Columbia University Press, 1996.

SÁ, S. P. Somos todos fãs e haters: cultura pop, afetos e performance de gosto nos sites de redes sociais. Revista Eco-Pós. Dossiê Cultura Pop. v. 19, n. 3, 2016.

SANDVOSS, C. Quando estrutura e agência se encontram: os fãs e o poder. Ciberlegenda, n. 28, 2013. Disponível em http://www. ciberlegenda.uff.br/index.php/revista/article/view/639/340. Acesso em: 13 maio 2019.

STRAW, W. Systems of articulation, logics of change: scenes and communities in popular music. Cultural Studies. v. 5, n. 3, 361-375, out. 1991.

TAYLOR, D. O arquivo e o repertório: performance e memória cultural nas américas. Belo Horizonte: Editora UFMG, 2013. 